Controlling Charging and Arcing on a Solar Powered Auroral Orbiting Spacecraft

\author{
Dale C. Ferguson \\ NASA Marshall Space Flight Center \\ and \\ Michael S. Rhee \\ NASA Goddard Space Flight Center
}

\begin{abstract}
:
The Global Precipitation Measurement satellite (GPM) will be launched into a high inclination (65 degree) orbit to monitor rainfall on a global scale. Satellites in high inclination orbits have been shown to charge to high negative potentials, with the possibility of arcing on the solar arrays, when three conditions are met: a drop in plasma density below $\sim 10,000 \mathrm{~cm}^{-3}$, an injection of energetic electrons of energy more that 7-10 $\mathrm{keV}$, and passage through darkness. Since all of these conditions are expected to obtain for some of the GPM orbits, charging calculations were done using first the Space Environment and Effects (SEE) Program Interactive Spacecraft Charging Handbook, and secondly the NASA Air-force Spacecraft Charging Analyzer Program (NASCAP-2k). The object of the calculations was to determine if charging was likely for the GPM configuration and materials, and specifically to see if choosing a particular type of thermal white paint would help minimize charging. A detailed NASCAP-2k geometrical model of the GPM spacecraft was built, with such a large number of nodes that it challenged the capability of NASCAP-2k to do the calculations.
\end{abstract}

The results of the calculations were that for worst-case auroral charging conditions, charging to levels on the order of -120 to -230 volts could occur on GPM during night-time, with differential voltages on the solar arrays that might lead to solar array arcing. In sunlit conditions, charging did not exceed $-20 \mathrm{~V}$ under any conditions. The night-time results were sensitive to the spacecraft surface materials chosen. For non-conducting white paints, the charging was severe, and could continue unabated throughout the passage of GPM through the auroral zone. Somewhat conductive (dissipative) white paints minimized the night-time charging to levels of - $120 \mathrm{~V}$ or less, and thus were recommended for GPM thermal control. It is shown that the choice of thermal control paints is important to prevent arcing on high inclination orbiting spacecraft solar arrays as well as for GEO satellites, even for solar array designs chosen to minimize arcing.

\title{
Introduction:
}

The Global Precipitation Measurement core satellite (GPM) is scheduled to be launched into an approximately $400 \mathrm{~km}$-altitude high-inclination orbit (65 degrees) in the year 2010. GPM is one of the earth observation satellite programs sponsored by the Japan Aerospace Exploration Agency (JAXA), the Japanese National Institute of Information and Communications Technology (NICT) and the National Aeronautics and Space Administration (NASA). It will use active phased array radars (DPR, dualfrequency precipitation radars) and a passive microwave radiometer to determine precipitation levels under its path. For temperature control, DPR will use a variety of materials (see table 1 below).

\begin{tabular}{|l|l|l|l|}
\hline \multirow{5}{*}{ Name } & Item no. & Mfg & Note \\
\hline \multirow{5}{*}{ White Paint } & AZ-93 & AZ Technology & non-conductive \\
\cline { 2 - 4 } & Z-93P & $\begin{array}{l}\text { Alion Science \& } \\
\text { Technology }\end{array}$ & non-conductive \\
\cline { 2 - 4 } & S13GP:6N/L0-1 & $\begin{array}{l}\text { Alion Science \& } \\
\text { Technology }\end{array}$ & non-conductive \\
\cline { 2 - 4 } & AZ-2100IECW & AZ Technology & conductive \\
\cline { 2 - 4 } & AZ-2000IECW & AZ Technology & conductive \\
\hline OSR (with ITO coating) & CMO-100-ITO & THALES & \\
\hline GBK & $166925-001$ & Sheldahl & $\begin{array}{l}\text { NASA } \\
\text { recommends }\end{array}$ \\
\hline Ag Teflon (with ITO coating) & 149598 & Sheldahl & \\
\hline
\end{tabular}

Table 1. Materials considered for thermal control of DPR. 
The choice of what white paint to use will be based partially on the spacecraft charging GPM will encounter while passing through the auroral zones. Non-conductive paints will charge more than conductive paints, and in the worst-case could lead to arcing on spacecraft surfaces or solar arrays. In this paper we present the results of calculations of DPR and GPM charging in worst-case auroral stream conditions, leading to a choice of white paint. These calculations will be of interest to others designing, building, and flying high-inclination orbiting satellites.

\section{Preliminary Calculations:}

Preliminary calculations were performed using the SEE Interactive Spacecraft Charging Handbook. The charging environment chosen was that of the Freja satellite charging events [Eriksson and Wahlund (2006)] except using a plasma density of $10^{6}$ electrons and ions per cubic meter, to simulate the density dropouts that Anderson (2005) has found to be so important for DMSP satellite charging. A model satellite with roughly the correct proportions of solar arrays to satellite body, and proportions of the different surface materials was constructed and subjected to the specified simulated auroral environment. In these calculations, Teflon was used as a substitute for non-conductive paint and black kapton was used to simulate conductive paint. The result of one such calculation is shown below in figure 1, using Teflon for non-conductive paint. Here it can be seen that charging continues unimpeded throughout the time period of the calculation.

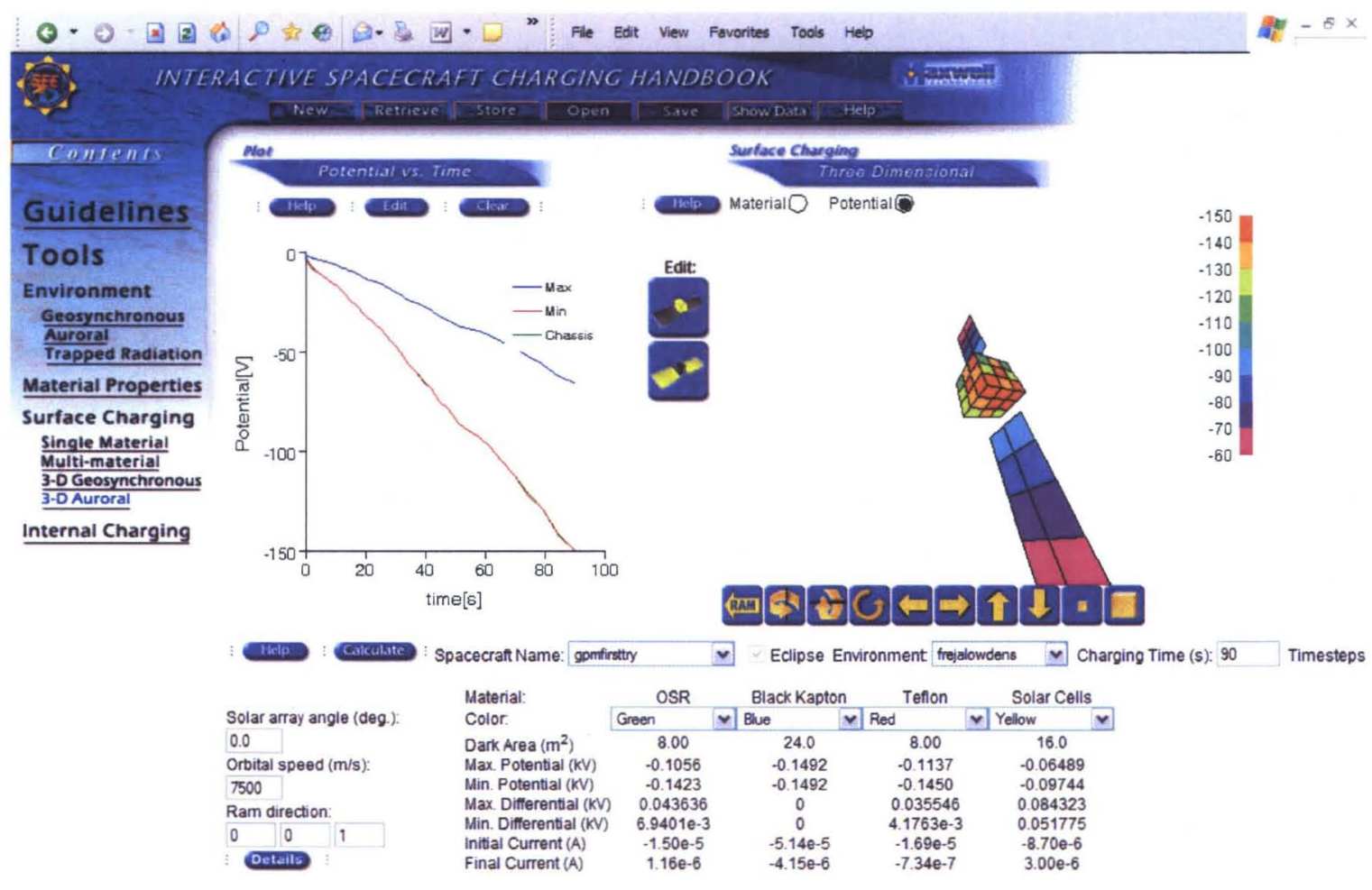

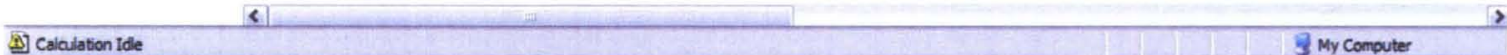

Figure 1. Preliminary charging calculation for GPM.

\section{Calculations Using NASCAP-2k:}

Final calculations were done using NASCAP-2k. A detailed spacecraft model was built, with nearly 2000 nodes, the maximum number allowed by NASCAP. NASCAP-2k has built-in material properties for many types of surface materials, but not for the representative non-conducting white paint (Z-93P) or the representative conductive white paint (AZ-2000). For those materials, measurements were made at the 
Goddard Space Flight Center, and were detailed in GSFC (2007). A table of some their measurement results is shown below:

\begin{tabular}{|c|c|c|c|c|c|c|}
\hline $\begin{array}{c}\text { Test } \\
\text { Sample }\end{array}$ & $\begin{array}{c}\text { Surface } \\
\text { Resistivity } \\
\text { (Ohms/Sq) } \\
\text { (Air) }\end{array}$ & $\begin{array}{c}\text { Surface } \\
\text { Resistivity } \\
\text { (Ohms/Sq) } \\
\text { (Vacuum) }\end{array}$ & $\begin{array}{c}\text { Volume } \\
\text { Resistivity } \\
\text { (Ohm-cm) } \\
\text { (Air) }\end{array}$ & $\begin{array}{c}\text { Volume } \\
\text { Resistivity } \\
\text { (Ohm-cm) } \\
\text { (Vacuum) }\end{array}$ & $\begin{array}{c}\text { Coating } \\
\text { Thickness }\end{array}$ & $\begin{array}{c}\text { Test Voltage } \\
\text { (SR,VR) }\end{array}$ \\
\hline AZ2000-2 & $2.37 \mathrm{E} 7$ & $3.42 \mathrm{E} 7$ & $7.18 \mathrm{E} 8$ & $3.72 \mathrm{E} 8$ & $7.4 \mathrm{E}-3 \mathrm{~cm}$ & $500 \mathrm{~V}, 100 \mathrm{~V}$ \\
\hline AZ2100-2 & $1.88 \mathrm{E} 9$ & $4.69 \mathrm{E} 11$ & $1.78 \mathrm{E} 10$ & $2.67 \mathrm{E} 14$ & $13.9 \mathrm{E}-3 \mathrm{~cm}$ & $500 \mathrm{~V}, 100 \mathrm{~V}$ \\
\hline Z93P-2 & $1.12 \mathrm{E} 11$ & $1.35 \mathrm{E} 15$ & $9.23 \mathrm{E} 11$ & $9.71 \mathrm{E} 15$ & $7.5 \mathrm{E}-3 \mathrm{~cm}$ & $100 \mathrm{~V}, 100 \mathrm{~V}$ \\
\hline AZ93-2 & $1.09 \mathrm{E} 12$ & $6.26 \mathrm{E} 13$ & $2.27 \mathrm{E} 11$ & $8.48 \mathrm{E} 12$ & $7.2 \mathrm{E}-3 \mathrm{~cm}$ & $100 \mathrm{~V}, 100 \mathrm{~V}$ \\
\hline
\end{tabular}

Table 2 - Resistivity properties of white paints for GPM.

In the words of the original report, all of the samples tested, except for the AZ2000 and AZ2100 samples, were resistive, whereas the "volume resistivity data indicates that the AZ2000-1, AZ2000-2 and AZ2100-1 are dissipative per ANSI/ESD S20.20-1999." That is, they can dissipate charge. Below are shown identical NASCAP-2k calculations of night-time charging of GPM using first (figures 2 and 3) Z93P and second (figures 3 and 4) AZ2000. Note the large differential potentials between conductors and insulators on the solar arrays in the Z93P case. These potentials are large enough to lead to arcing on solar array panels in LEO conditions. To avoid them dissipative paints such as AZ2000 should be used instead of non-conductive paints such as Z93P.

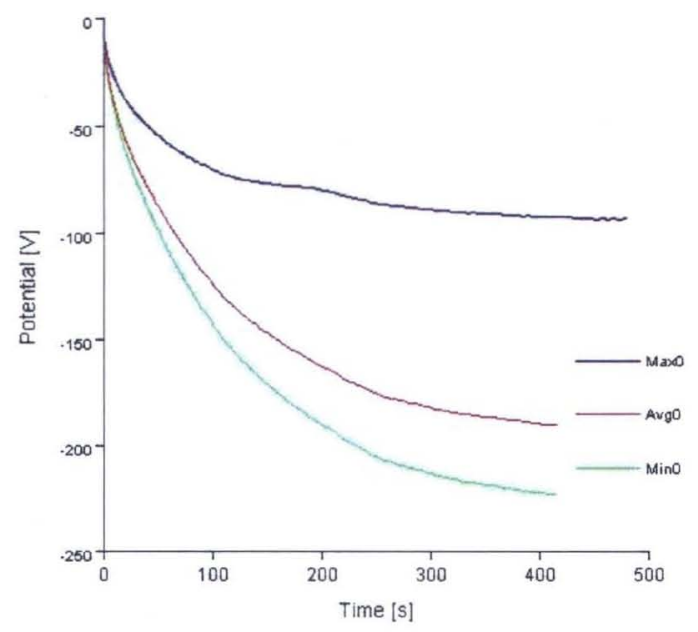

Figure 2. Charging history of night-time Z93P paint GPM model. 


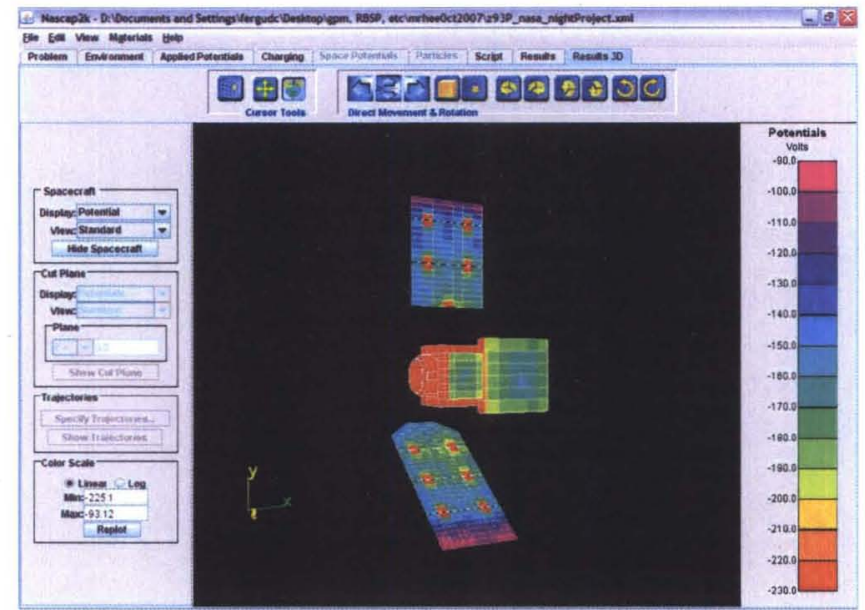

Figure 3. 3-D view of final charging on night-time Z93P paint GPM model.

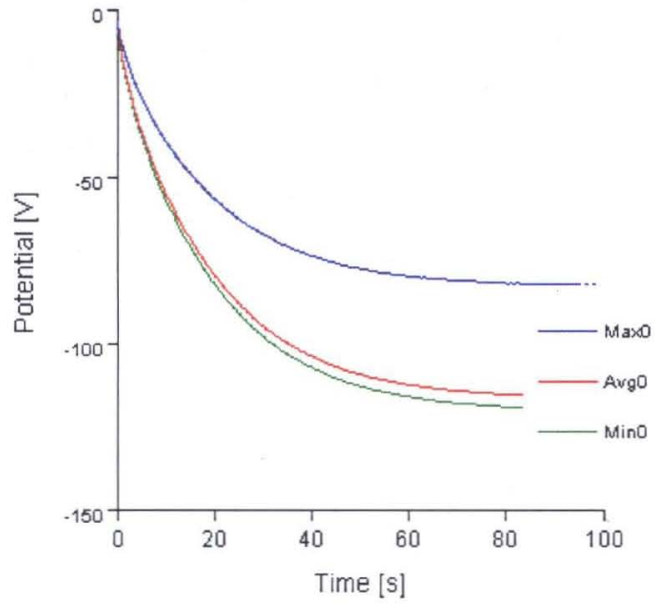

Figure 4. Charging history of night-time AZ2000 paint GPM model. 


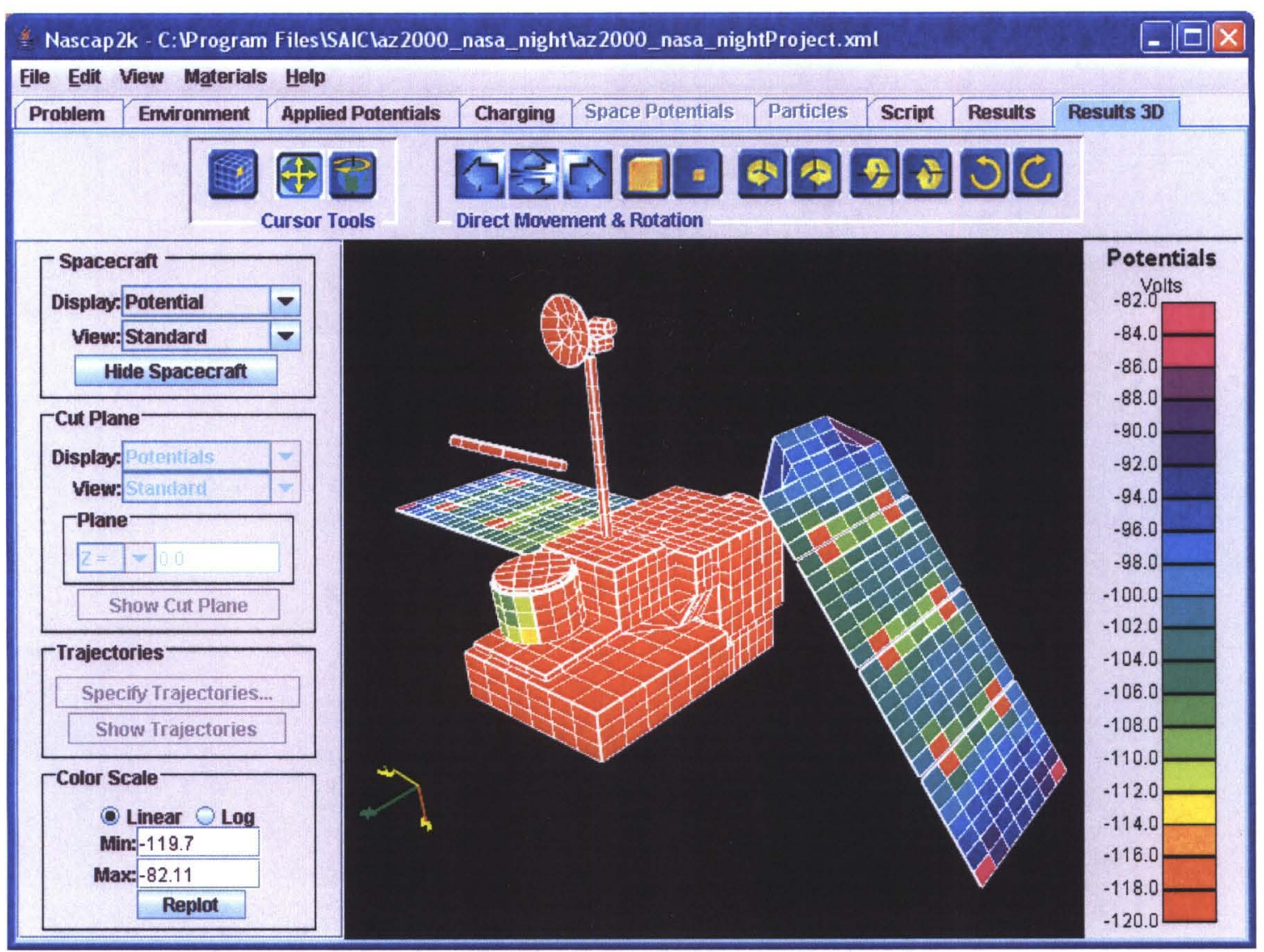

Figure 3. 3-D view of final charging on night-time AZ2000 paint GPM model.

\section{Conclusions:}

The choice of thermal paints can have a significant effect on charging of satellites in auroral zone conditions, as well as for GEO satellites. To prevent charging and arcing on auroral orbiting satellites, the use of dissipative paints, such as AZ2000, is recommended.

\section{References:}

Anderson, P.C., 2005. Spacecraft Charging Hazards In Low-Earth Orbit, Proceedings of the $9^{\text {th }}$ Spacecraft Charging Technology Conference, Tsukuba, Japan, April 4-8, 2005, JAXA-SP-05-001E, Paper 091 and.pdf.

Eriksson, A.I.; Wahlund, J.-E., 2006. Charging of the Freja Satellite in the Auroral Zone, IEEE Transactions on Plasma Science, Volume 34, Issue 5, Oct. 2006 Page(s):2038 - 2045.

GSFC, 2007. NASA-Goddard Space Flight Center, Materials Engineering Branch, Code 541/BATC Laboratory Report, Date: 11/15/07, Analysis \#: 2007-012, Project: GPM. 


\title{
Controlling Charging and Arcing on a Solar Powered Auroral Orbiting Spacecraft
}

\author{
Dale C. Ferguson \\ NASA Marshall Space Flight Center \\ and \\ Michael S. Rhee \\ NASA Goddard Space Flight Center
}




\section{Introduction:}

- The Global Precipitation Measurement core satellite (GPM) is scheduled to be launched into an approximately $400 \mathrm{~km}$-altitude high-inclination orbit (65 degrees) in the year 2010.

- GPM is one of the earth observation satellite programs sponsored by the Japan Aerospace Exploration Agency (JAXA), the Japanese National Institute of Information and Communications Technology (NICT) and the National Aeronautics and Space Administration (NASA).

- It will use active phased array radars (DPR, dualfrequency precipitation radars) and a passive microwave radiometer to determine precipitation levels under its path.

- For temperature control, DPR will use a variety of materials (see table 1 on next page). 


\section{GPM/DPR Thermal Control Material Candidates}

\begin{tabular}{|c|c|c|c|}
\hline Name & Item no. & Mfg & Note \\
\hline \multirow[t]{5}{*}{ White Paint } & AZ-93 & AZ Technology & non-conductive \\
\hline & Z-93P & Alion Science \& Technology & non-conductive \\
\hline & S13GP:6N/L0-1 & Alion Science \& Technology & non-conductive \\
\hline & AZ-2100IECW & AZ Technology & conductive \\
\hline & AZ-2000IECW & AZ Technology & conductive \\
\hline OSR (with ITO coating) & CMO-100-ITO & THALES & \\
\hline GBK & $166925-001$ & Sheldahl & NASA recommends \\
\hline Ag Teflon (with ITO coating) & 149598 & Sheldahl & \\
\hline
\end{tabular}




\section{Preliminary Calculations:}

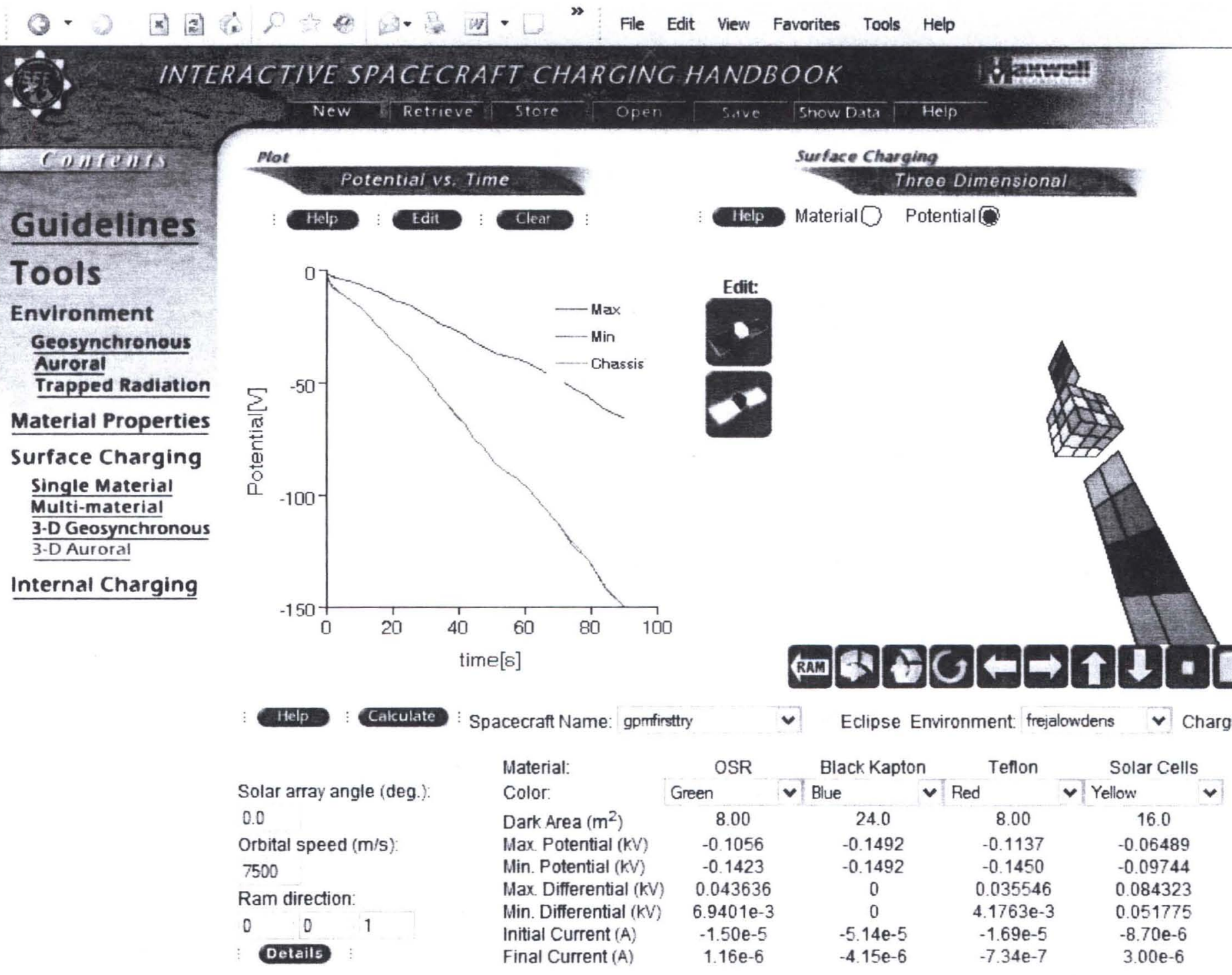




\section{Calculations Using NASCAP-2k: Inputs}

\begin{tabular}{|c|c|c|c|c|c|c|}
\hline Test Sample & $\begin{array}{c}\text { Surface } \\
\text { Resistivity } \\
\text { (Ohms/Sq) } \\
\text { (Air) }\end{array}$ & $\begin{array}{c}\text { Surface } \\
\text { Resistivity } \\
\text { (Ohms/Sq) } \\
\text { (Vacuum) }\end{array}$ & $\begin{array}{c}\text { Volume } \\
\text { Resistivity } \\
\text { (Ohm-cm) } \\
\text { (Air) }\end{array}$ & $\begin{array}{c}\text { Volume } \\
\text { Resistivity } \\
\text { (Ohm-cm) } \\
\text { (Vacuum) }\end{array}$ & Coating Thickness & $\begin{array}{c}\text { Test Voltage } \\
\text { (SR,VR) }\end{array}$ \\
\hline AZ2000-2 & $2.37 \mathrm{E} 7$ & $3.42 \mathrm{E} 7$ & $7.18 \mathrm{E} 8$ & $3.72 \mathrm{E} 8$ & $7.4 \mathrm{E}-3 \mathrm{~cm}$ & $500 \mathrm{~V}, 100 \mathrm{~V}$ \\
\hline AZ2100-2 & $1.88 \mathrm{E} 9$ & $4.69 \mathrm{E} 11$ & $1.78 \mathrm{E} 10$ & $2.67 \mathrm{E} 14$ & $13.9 \mathrm{E}-3 \mathrm{~cm}$ & $500 \mathrm{~V}, 100 \mathrm{~V}$ \\
\hline Z93P-2 & $1.12 \mathrm{E} 11$ & $1.35 \mathrm{E} 15$ & $9.23 \mathrm{E} 11$ & $9.71 \mathrm{E} 15$ & $7.5 \mathrm{E}-3 \mathrm{~cm}$ & $100 \mathrm{~V}, 100 \mathrm{~V}$ \\
\hline AZ93-2 & $1.09 \mathrm{E} 12$ & $6.26 \mathrm{E} 13$ & $2.27 \mathrm{E} 11$ & $8.48 \mathrm{E} 12$ & $7.2 \mathrm{E}-3 \mathrm{~cm}$ & $100 \mathrm{~V}, 100 \mathrm{~V}$ \\
\hline
\end{tabular}

Resistivity properties of white paints for GPM.

GSFC (2007) 


\section{Calculations Using NASCAP-2k: Results}

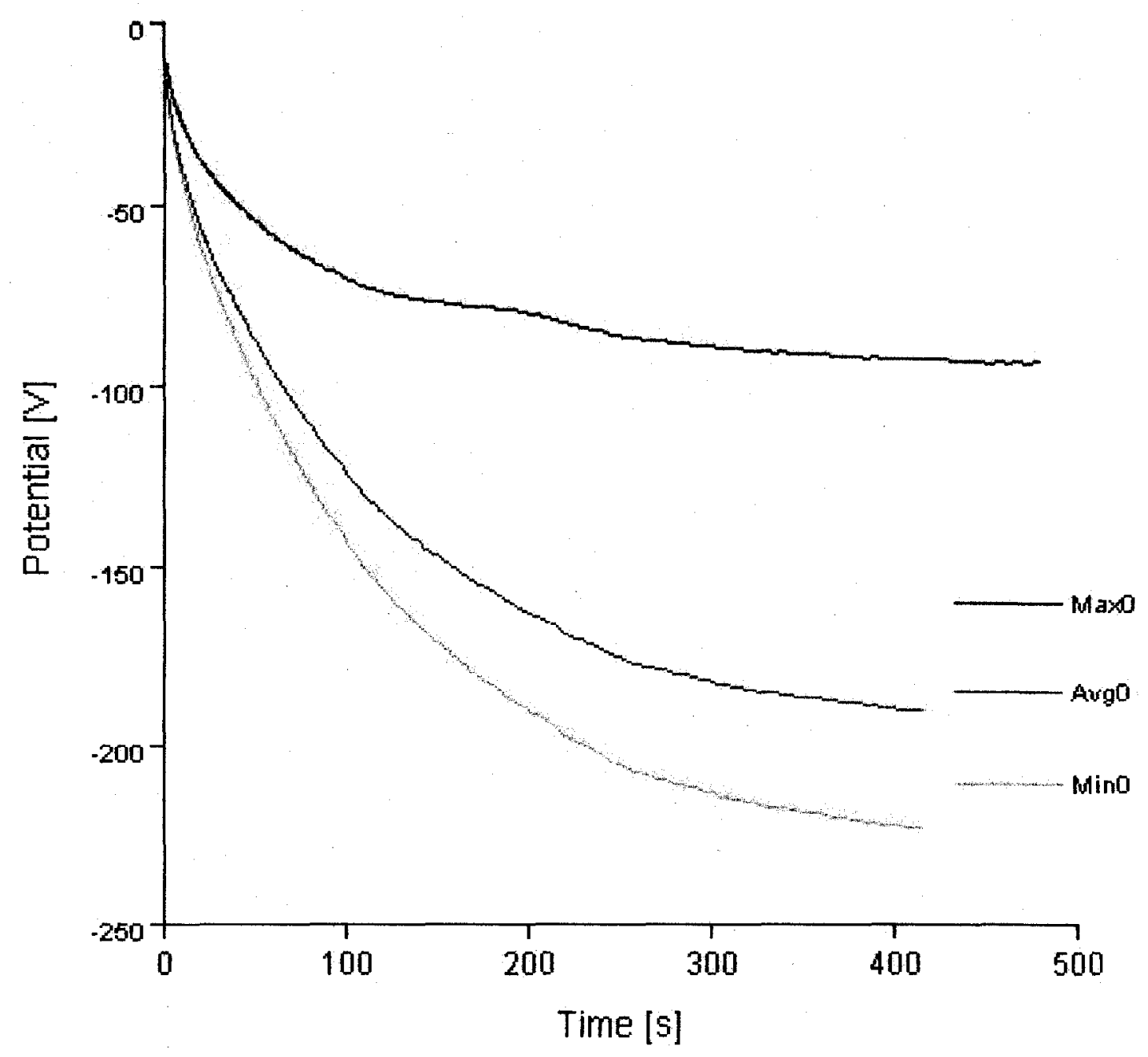

Charging history of night-time Z93P paint GPM model. 


\section{Calculations Using NASCAP-2k: Results}

14. Nascap2k - D:Wocuments and SettingslfergudclDesktoplgpm, RBSP, etclmrhee0ct20077293P_nasa_nightProject.xml Elle Edit View Materials Help

Problem Erivironment Applied Potentials Charging Space Potentixis Particles Script Results Results 3D
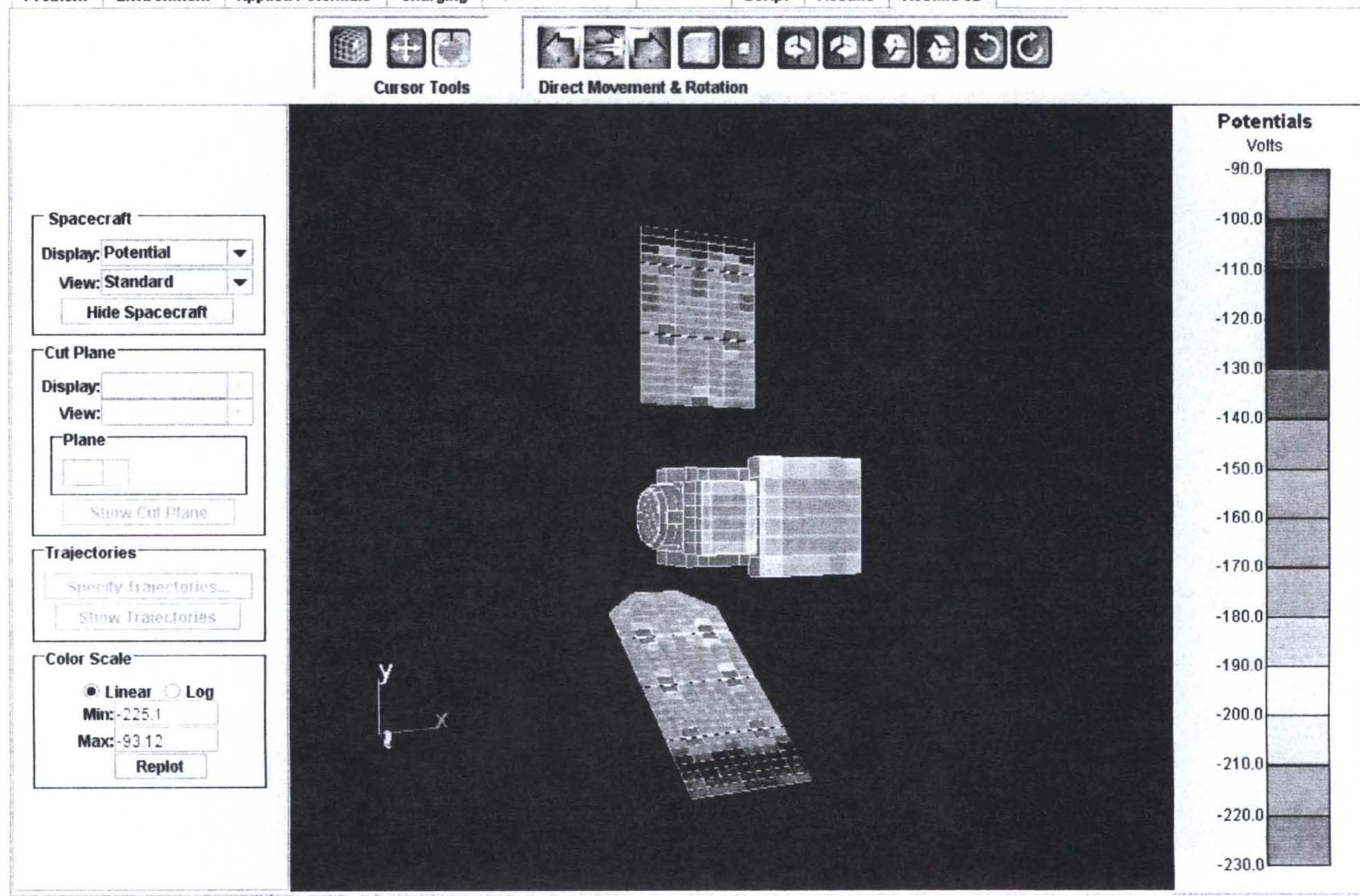

3-D view of final charging on night-time Z93P paint GPM model. 


\section{Calculations Using NASCAP-2k: Results}

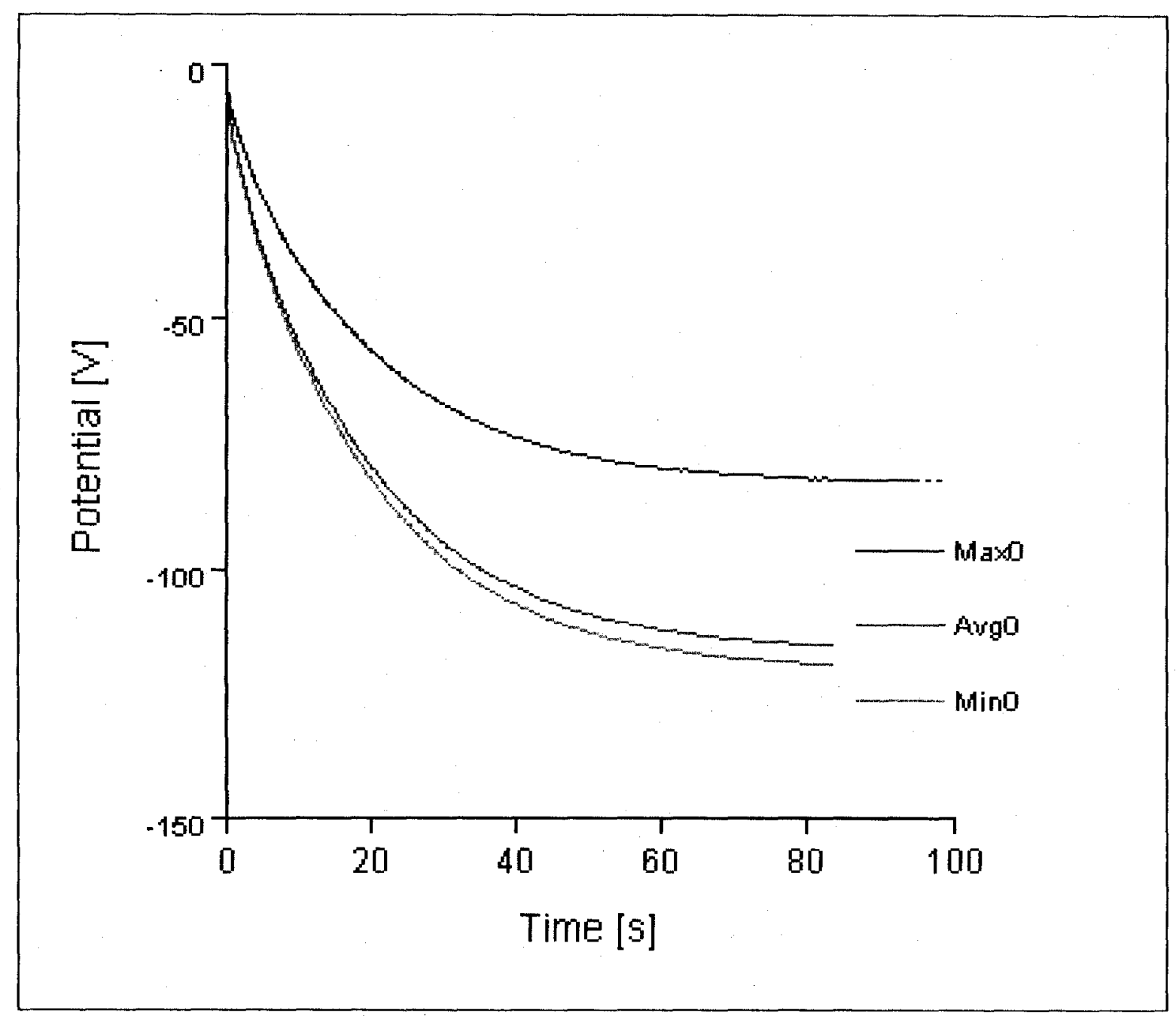

Charging history of night-time AZ2000 paint GPM model. 


\section{Calculations Using NASCAP-2k: Results}

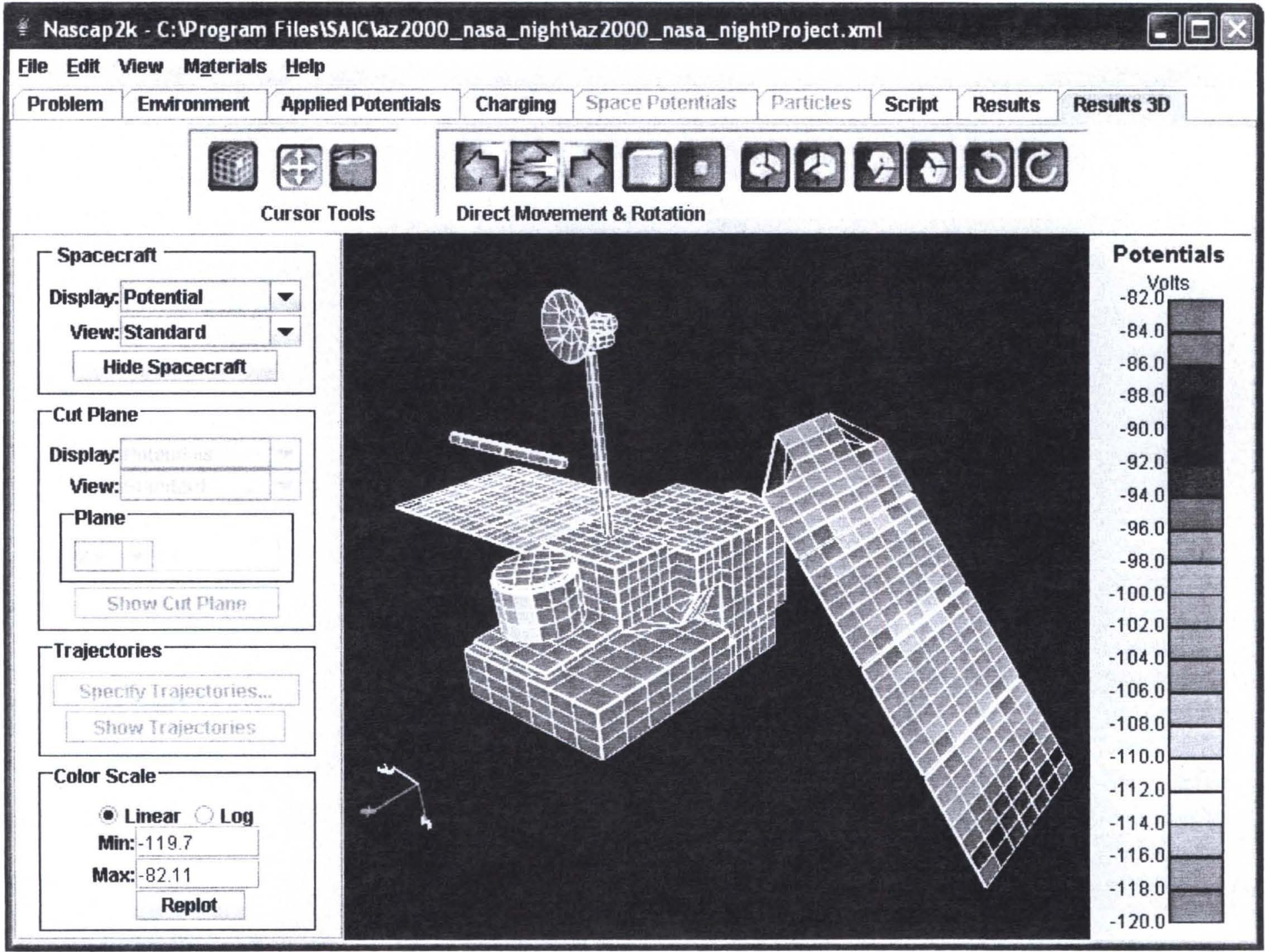

3-D view of final charging on night-time AZ2000 paint GPM model. 


\section{Conclusions:}

- The choice of thermal paints can have a significant effect on charging of satellites in auroral zone conditions, as well as for GEO satellites.

- To prevent charging and arcing on auroral orbiting satellites, the use of dissipative paints, such as AZ2000, is recommended. 